\title{
Application of Logistic Regression in Determining the Factors Influencing the use of Modern Contraceptive among married women in Ethiopia
}

\author{
Kebede Abu Aragaw \\ Department of Statistics, Arba Minch University, Arba Minch, Ethiopia
}

Email address:

kebedeabu@gmail.com

To cite this article:

Kebede Abu Aragaw. Application of Logistic Regression in Determining the Factors Influencing the use of Modern Contraceptive among married women in Ethiopia. American Journal of Theoretical and Applied Statistics. Vol. 4, No. 3, 2015, pp. $156-162$.

doi: $10.11648 /$ j.ajtas.20150403.21

\begin{abstract}
The aim of the study was to investigate the determinants of use of modern contraceptive among married women in Ethiopia. Our study is based on the data taken from a nationally representative survey EDHS of 2011. The sample includes 9,438 married women aged 15-49 years. Cross tabulations were carried out at the bivariate level to assess the association between contraceptive use and each of the explanatory variables and binary multiple logistic regression analysis was used to identify the factors influencing modem contraceptive use among married women in Ethiopia. The bivariate analysis reveals statistically significant association between all explanatory variables i.e age of woman, region, religion, place of residence, education level of woman, number of living children, desire for more children, wealth status, and decision maker for modern contraception, educational level of husband, modern contraceptive knowledge and exposure to media. Results for binary multiple logistic regression analysis reveals that age of woman have a statistically significant positive effect on modern contraceptive use. Contraceptive use was highest in the age group of 15 to 19 years while it was lowest among married women aged 40-44 years compared to those married women aged 45-49 years as reference category. Furthermore, uneducated women and women not at work want no more children. The lowest wealth status women are less likely to use modern contraception compared to their corresponding reference group. The result also shows that married women who do not discuss about family planning with their husbands use modern contraception $25.6 \%$ less in comparison to those couples made decisions jointly. Generally men play a critical role in determining the size of their family. Male involvement, therefore, is an integral component of successful reproductive health programs. But binary logistic regression results do not support the hypothesis that educational levels of husband have influence on the use of modem contraceptive methods among women. Media exposure is another factor that influences modem contraceptive use. The odds of married women who were not exposed to media are $35.8 \%$ less likely in using a modern contraception method than those who had media exposure.
\end{abstract}

Keywords: Family Planning, Modern Contraceptives, Married Women, EDHS, Logistic Regression Models, Ethiopia

\section{Introduction}

Rapid population growth, which in many instances far outstrips economic growth and environmental sustainability, is the reality in most developing countries of sub-Saharan Africa (UNDP, 1992). The type of development which involves complex interconnected processes of expanding education, health, employment and other basic needs provides the chief ingredient for lasting demographic transition with markedly reduced fertility and mortality (Speth, 1994). Cohen (1998) suggests that sub-Sahara is among the major regions of the developing world that have not yet undergone a general decline in fertility. Ethiopia is the second most populous country in the sub-Saharan Africa next to Nigeria, with population growth rate of 2.6 percent per year and the total fertility rate approximate to 5 ( CSA, 2007). Factors contributing to high fertility include low socio-economic development, deeply-ingrained cultural values for large family size, and low levels of contraception (Bertrand, 2003). Issues related to childbearing and birth control in the African continent, especially the sub-Saharan region, are of policy interest because of unusual increases in population growth this 
area has experienced in the past decade (USAID, 2009).

As a consequence, the question of how fertility is expected to decline in the presence of family planning programs that promote contraceptive measures is of theoretical as well as policy importance. It is believed that family planning program through promoting the use of contraceptive use have played an important role in reducing high fertility and its negative effects on health and development. In the early stage of an implementation of the program, its focus is to motivate couples to adopt contraceptive use. Therefore, contraceptive prevalence has been used as an indicator to evaluate the implementation of family planning program (Amaha and Fikre, 2006).

Contraception is defined as a practice of methods of preventing or planning of conception. Contraceptive methods can be modern, traditional and folkloric methods of contraception. Among the methods, modern method of contraception includes intra uterine device (IUD), oral contraceptives, Pill, Injectables, condom, LAM etc; traditional method included periodic abstinence, withdrawal while folkloric method included use of herbs etc.

Birth control has become more common in less developed countries, and this growth has been in the form of modern methods of contraceptive use (Gille, 1985). Hanks (2003) argue that since most traditional contraceptive methods like withdrawal and "counting" are behavioural they are unpredictable. According to (Trussel and Kost, 1987) modern contraceptive methods are more effective in preventing pregnancies.

The EDHS 2011 report indicates that use of modern contraceptive methods among currently married women has increased from 2000, 2005 and 2011 by $6 \%, 14 \%, 27 \%$ respectively while the trends of traditional methods use remains the same for 2005 and 2011 about $1 \%$. The increase in modern method use is attributed primarily to the sharp increase in the use of injectables, from $3 \%$ in 2000 to $21 \%$ in 2011.

Statement of the Problem

It is believed that population growth and family planning are closely related concepts. Family planning is being prevalently used in different countries to make population growth parallel with economic growth. The population growth of many developing countries is found to be exponential (Shryock and Siegel, 1976). It is critical for family planning workers to continue to meet the needs of existing contraceptive users, and also to address barriers for contraceptive users in the society since, individual interests, behaviors, etc. differ from one unit to another within each level, owing to variability among various socioeconomic and geographical factors such as religion, culture, income, place of residence, education, occupation, mass media access, administrative and social facilities, and so on. Ethiopia is one of developing countries, which is motivating women to use family planning currently. This issue led us to generate ideas by identifying factors influencing the use of modern contraceptives in Ethiopia among women of childbearing age.

\section{Objectives of the Study}

\subsection{General Objective}

The general objective of the study is to determine the factors which influence the use of modern contraceptive use among married women aged 15-49 years in Ethiopia.

The specific objectives of the study are:

- To identify socio-economic, demographic and other proximate factors that affect the use of modern contraceptive methods among married women of child bearing age in Ethiopia.

- To provide relevant recommendations for policy makers and suggest directions for future studies.

\subsection{Data and Methodology}

\subsubsection{Source of Data}

This study used secondary data from the 2011 Ethiopian Demographic and Health Survey (EDHS) obtained from Central Statistical Agency (CSA, 2011).

\subsubsection{Description of Variables}

\section{(i) Dependent (response) Variable}

The response variable included in this study is modern contraceptives use or non-use. Hence, the response variable $y_{i}$ for $\mathrm{i}^{\text {th }}$ woman can be expressed as: 1 those women who were using modern contraceptive method and those who were not using modern contraceptive method are coded as 0 .

\section{(ii) Explanatory Variables}

The independent variables that are used in the study were classified as demographic, socio-economic covariates and other variables. Variables such as age and sex are considered as demographic variables, while others like wealth index and religious affiliation considered as socio-economic variables.

\subsection{Method of Data Analysis}

\subsubsection{Binary Logistic Regression}

With binary logistic regression we estimate the probability of a dichotomous response (which of course is also its mean) for various values of explanatory variables. We fit a following model of the form

$$
E(y)=\frac{e^{\beta_{0}+\beta_{1} x}}{1+e^{\beta_{0}+\beta_{1} x}}
$$

the expression on the right side, called a logistic function, In the above function, the relationships between $\mathrm{p}$ and $\mathrm{x}$ are non-linear and can be linearized. Let be the linear predictor where is defined by the transformation

This transformation is called the logit transformation of the probability $\mathrm{p}$ and the ratio is called the odds. Sometimes the logit transformation is called log odds. And hence, multiple logistic regression model logistic with $\mathrm{k}$ independent variablecan be written as: 


$$
\eta=\ln \frac{p}{1-p}=\mathrm{X}^{\prime} \beta=\beta_{0}+\beta_{1} x_{1}+\ldots .+\beta_{p} x_{k}
$$

\subsubsection{Fitting the Logistic Regression Model}

Logistic regression uses a maximum likelihood estimation technique to estimate parameters in the model. In other words, ML finds the best values for

$$
\eta=\beta_{0}+\beta_{1} x_{1}+\ldots . .+\beta_{k} x_{k}
$$

Observed values of say,are the $\mathrm{n}$ independent random observations corresponding to the random variables $\left(\mathrm{Y}_{1}\right.$, $\left.Y_{2}, \ldots, Y_{n}\right)$. Since the $Y_{i}$ is a Bernoulli random variable with functional form and hence, the likelihood function of is given by :

$$
\ell(\beta, \mathrm{Y})=\prod_{i=1}^{n} p^{y_{i}}(1-p)^{1-y_{i}}
$$

The estimation of parameters, require the maximization of the likelihood function or equivalently the maximization of the natural logarithm of the likelihood function.

In this study, SPSS is used for analyzing the data.

\subsubsection{Model Building and Steps for Variable Selection}

The following steps are recommended by (Hosmer and Lemeshow, 1989) to aid in the selection of variables for a logistic regression. Firstly, the selection process should begin with univariate analysis of each variable. Secondly, selection of variables for the multiple regressions will follow the results in the univariate analysis. Finally, the importance of each variable included in the multiple regression models should be verified by different model assessment techniques. Weemployed stepwise selection algorithm to select predictor variables which influence jointly the response. We also used the likelihood Ratio Test, Wald Test and $\mathrm{R}^{2}$ type statistics for assessing the goodness of fit of the model and model adequacy has been checked by using detection of outliers and influence diagnostics.

\section{Statistical Data Analysis}

\subsection{Multivariable Analysis of Factors Influencing Modern Contraceptive Use Among Married Women In Reproductive Age Group}

The results of the binary logistic regression are given in Table 3.1 which displays the coefficients, odds ratio, significance level (p-value) and Wald statistic for the odds ratio and coefficients associated with each of the independent variable entered into the logistic regression model. The result of chi-square shows that covariates age of women, religion, place of residence, region, wealth index, number of living children, women's educational level, desire for more children, knowledge about modern contraception, working status of women, decision maker for using modern contraception and exposure to mass media were significant at 5\% level significance. However, educational level of husband was found to be statistically in significant.
Binary logistic regression analysis revealed controlling other variables in the model, the odds of married women aged 15-19 were 8.123 times more likely to use modern contraception than those aged 45-49 years which is the reference category. Similarly, the odds of using modern contraceptives among married women in the age 20-24, 25-29, are 6.952 times (OR: 6.952, CI: $(5.064,9.544))$ and 5.363 times (OR: 5.363 , CI: $(3.980,7.226)$ ), respectively, higher than that of married women in the age group 45-49.The odds of married women who were 30-34 years old are 3.722 times and 35-49 years old are 3.629 higher than times the odds of those who were aged 45-49 in terms of using modern contraception. The result shows that odds of using modern contraception decrease as age of married women increase.

The odds of using modern contraceptive of married women in Amhara are 2.227 times (OR: 2.227, CI: $(1.674,2.964))$ higher than that the odds using modern contraceptive of married women in Addis Ababa.

Married women who lived in Benshangul- Gumuz were 77.6 percent more likely to use contraceptives compared to women in Addis Ababa. Conversely, Married women who lived in Somali were $79 \%$ less likely to use modern contraceptive methods as compared to married women in Addis Ababa. While the odds of married women living in Tigray, Afar andHarari were not significant, indicating that modern contraceptive use in these region is similar to Addis Ababa.

Married women who were followers of orthodox religion were 2.274 times (OR: 2.274, CI: (1.469, 3.522)) more likely to use contraceptives than those who were followers of religions other than Coptic Orthodox, Protestant and Muslim. Protestant married women were 68 percent more likely to use modern contraceptives compared to those who were followers of religions other than Orthodox, Protestant and Muslim. The likelihood of using contraceptive methods among married women who were followers of Muslim was not significantly different from those who were followers of religions other than Orthodox, protestant and Muslim.

Married women who resided in the rural areas were $94.4 \%$ more likely to use modern contraceptive compared to those married women living in urban areas.

Married women who didn't have knowledge of modern contraceptive methods are $73.4 \%$ less likely to use modern contraceptive methods as compared to those who have knowledge of modern contraceptive use.

Married women who were poor and middle wealth status were less likely to use modern contraception (61 \% and $38 \%$ respectively) than those in the rich wealth status which is the reference group.

Married women who had not discussed about family planning with their husbands were $25.6 \%$ less likely to use the modern contraception than those made decisions jointly. However, married women who were leaving family planning decisions to their husbands alone were $30.9 \%$ less likely to use modern contraception compared to those decisions made jointly.

As compared to married women who had 2 and more children, women with no living child were $64 \%$ less likely to 
use modern contraception(OR: $0.360, \mathrm{CI}:(0.286,0.454))$ than those married women with 2 and more children. Similarly, the odds of married women with one child were $16.2 \%$ less likely to practice modern contraception than those with two or more children.

As expected, married women who wanted no more children were $36 \%$ less likely to use modern contraceptive than women who desired to have another child which is the reference category.

Regarding women's education, it shows that women with no education were $23.4 \%$ less likely to use modern contraception and women with primary education level were 3\% less likely to use modern contraception than those with secondary and higher level education. In addition, women working status was also statistically significant. The odds of married women who were not working are $20.5 \%$ lower than the odds of married women who were engaged at work.

The odds of married women who were not exposed to media are $35.8 \%$ less likely to use modern contraception as compared to married women those exposed to media. However, there were not statistically significant between users and non-users among married women's in terms of husband's education.

Table 3.1. Results of Binary Logistic Regression Analysis for modern contraceptive use among married women in child bearing age by demographic, socioeconomic and proximate factors.

\begin{tabular}{|c|c|c|c|c|c|c|c|c|}
\hline \multirow{2}{*}{ Variables } & \multirow{2}{*}{ B } & \multirow{2}{*}{ S.E. } & \multirow{2}{*}{ Wald } & \multirow{2}{*}{ Df } & \multirow{2}{*}{ Sig. } & \multirow{2}{*}{$\operatorname{Exp}(\beta)$} & \multicolumn{2}{|c|}{ 95\% C.I. for $\operatorname{Exp}(\beta)$} \\
\hline & & & & & & & Lower & Upper \\
\hline \multicolumn{3}{|l|}{ Age (Ref: 45-49) } & 180.549 & 6 & $.000 *$ & & & \\
\hline $15-19$ & 2.095 & .191 & 119.921 & 1 & $.000 *$ & 8.123 & 5.583 & 11.818 \\
\hline $20-24$ & 1.939 & .162 & 143.857 & 1 & $.000 *$ & 6.952 & 5.064 & 9.544 \\
\hline $25-29$ & 1.679 & .152 & 121.818 & 1 & $.000 *$ & 5.363 & 3.980 & 7.226 \\
\hline $30-34$ & 1.613 & .154 & 109.940 & 1 & $.000 *$ & 5.017 & 3.711 & 6.783 \\
\hline $35-39$ & 1.589 & .153 & 107.588 & 1 & $.000 *$ & 4.901 & 3.629 & 6.617 \\
\hline $40-44$ & 1.020 & .165 & 38.050 & 1 & $.000 *$ & 2.773 & 2.005 & 3.834 \\
\hline \multicolumn{3}{|l|}{ Region (Ref: Addis Ababa) } & 164.023 & 10 & $.000 *$ & & & \\
\hline Tigray & -.048 & .157 & .093 & 1 & .760 & .953 & .701 & 1.297 \\
\hline Afar & -.129 & .161 & .638 & 1 & .425 & .879 & .641 & 1.206 \\
\hline Amhara & .805 & .146 & 30.481 & 1 & $.000 *$ & 2.237 & 1.681 & 2.976 \\
\hline Oromiya & .319 & .139 & 5.266 & 1 & $.022 *$ & 1.375 & 1.048 & 1.805 \\
\hline Somali & -1.565 & .260 & 36.317 & 1 & $.000 *$ & .209 & .126 & .348 \\
\hline Benshangul-Gumuz & .577 & .149 & 14.938 & 1 & $.000 *$ & 1.782 & 1.329 & 2.388 \\
\hline SNNP & .327 & .156 & 4.375 & 1 & $.036 *$ & 1.387 & 1.021 & 1.883 \\
\hline Gambela & .522 & .167 & 9.826 & 1 & $.002 *$ & 1.685 & 1.216 & 2.336 \\
\hline Harari & .145 & .154 & .894 & 1 & .344 & 1.157 & .856 & 1.563 \\
\hline Dire Dawa & .546 & .150 & 13.176 & 1 & $.000 *$ & 1.726 & 1.285 & 2.317 \\
\hline \multicolumn{9}{|l|}{ Place of residence(Ref: urban) } \\
\hline Rural & .665 & .084 & 62.968 & 1 & $.000 *$ & 1.944 & 1.650 & 2.291 \\
\hline Religion(Ref: other) & & & 74.520 & 3 & $.000 *$ & & & \\
\hline Orthodox & .820 & .223 & 13.519 & 1 & $.000 *$ & 2.272 & 1.467 & 3.518 \\
\hline Protestant & .518 & .220 & 5.541 & 1 & $.019 *$ & 1.679 & 1.091 & 2.586 \\
\hline Muslim & .199 & .223 & .792 & 1 & .373 & 1.220 & .787 & 1.890 \\
\hline Wealth & & & 155.505 & 2 & $.000 *$ & & & \\
\hline Poor & -.945 & .076 & 155.359 & 1 & $.000 *$ & .389 & .335 & .451 \\
\hline Middle & -.476 & .087 & 29.695 & 1 & $.000 *$ & .621 & .523 & .737 \\
\hline \multicolumn{9}{|c|}{ Knowledgeof modern contraception (Ref: yes) } \\
\hline No & -1.324 & .238 & 31.007 & 1 & $.000 *$ & .266 & .167 & .424 \\
\hline \multicolumn{3}{|c|}{ Number of living Children(Ref: 2 or more children ) } & 76.914 & 2 & $.000 *$ & & & \\
\hline No child & -1.021 & .118 & 75.175 & 1 & $.000 *$ & .360 & .286 & .454 \\
\hline 1 child & -.165 & .083 & 3.917 & 1 & .048 & .848 & .720 & 0.998 \\
\hline \multicolumn{9}{|c|}{ Desire for more children (Ref: wants more) } \\
\hline Wants no more & -.444 & .063 & 50.166 & 1 & $.000 *$ & .642 & .567 & .725 \\
\hline \multicolumn{9}{|c|}{ Women's work status(Ref:working) } \\
\hline Not working & -.230 & .058 & 15.790 & 1 & $.000 *$ & .795 & .710 & .890 \\
\hline \multicolumn{3}{|c|}{ Education level of women(Ref: secondary and higher) } & 16.014 & 2 & .000 & & & \\
\hline No education & .185 & .056 & 10.952 & 1 & .001 & 1.203 & 1.078 & 1.342 \\
\hline Primary & .246 & .086 & 8.110 & 1 & .004 & 1.279 & 1.080 & 1.515 \\
\hline \multicolumn{3}{|c|}{ Decision maker for use(Ref: joint decision ) } & 16.288 & 2 & .000 & & & \\
\hline Wife & -.296 & .074 & 16.079 & 1 & .000 & .744 & .643 & .859 \\
\hline Husband & -.169 & .052 & 10.562 & 1 & .002 & .691 & .423 & 0.928 \\
\hline \multicolumn{3}{|c|}{ Education level of husband(Ref: secondary and higher) } & .937 & 2 & .626 & & & \\
\hline No education & .067 & .083 & .646 & 1 & .422 & 1.069 & .908 & 1.259 \\
\hline Primary & .082 & .085 & .917 & 1 & .338 & 1.085 & .918 & 1.282 \\
\hline \multicolumn{9}{|c|}{ Exposure to any media (Ref: yes) } \\
\hline No & -.444 & .063 & 49.281 & 1 & $.000 *$ & .642 & .567 & .726 \\
\hline Constant & -2.300 & .317 & 52.690 & 1 & $.000 *$ & .100 & & \\
\hline
\end{tabular}




\subsection{Goodness of Fit of the Logistic Regression Model}

For Goodness of fit of the model we applied likelihood ratio test and omnibus test and found that all predictors are significant. In case LR test, the statistic for the model that had only the intercept is $-2 \mathrm{LLO}=15.507+8385.829=8401.336$. The inclusion of the parameters reduced the -2 Log Likelihood statistics by $8401.336-8385.829=15.507$, which is reflected in the model chi-square for omnibus test given on Table 3.2 at appendix

Table 3.2. Omnibus Tests of Model Coefficients.

\begin{tabular}{llll}
\hline & Chi-square & Df & p-value \\
\hline Step & 1842.267 & 34 & $.000^{*}$ \\
Block & 1842.267 & 34 & $.000^{*}$ \\
Model & 1842.267 & 34 & $.000^{*}$ \\
\hline
\end{tabular}

(* Significant at 5\% level)

\subsection{Model Summary of Binary Logistic Regression Model}

The "pseudo" $\mathrm{R}^{2}$ estimates in the Table 3.3indicate that, approximately $17.6 \%$ or $26.7 \%$ of the variance inmarried women in Ethiopia whether using or not using modern contraceptives can be predicted from the linear combination of all variables supposed to be predictors of modern contraceptives use. The Cox and Snell $R^{2}(17.6 \%)$ is usually an underestimate. The Nagelkerke $\mathrm{R}$ square is estimated at $26.7 \%$ indicating that all variables are useful in predicting modern contraceptive use of married women in Ethiopia.

Table 3.3. Model Summary of Binary Logistic Regression.

\begin{tabular}{llll}
\hline Step & $\begin{array}{l}\mathbf{- 2} \text { Log } \\
\text { likelihood }\end{array}$ & Cox \& Snell R Square & $\begin{array}{l}\text { Nagelkerke R } \\
\text { Square }\end{array}$ \\
\hline 1 & $8395.823^{\mathrm{a}}$ & .176 & .267 \\
\hline
\end{tabular}

a. Estimation terminated at iteration number 6 because parameter estimates changed by less than .001 .

\subsection{Hosmer and Lemeshow Test of Goodness fit of Binary Logistic Regression Analysis}

Goodness-of-fit statistics helps to determine whether the model adequately described the data. The Hosmer-Lemeshow statistics Table 3.4 indicates a poor fit if the significant value is less than 0.05 .

The classification Table 3.5 shows that with the cutoff set at $0.5,29.3$ percent of women who were using contraceptive were correctly classified whereas 94.2 percent of women who were not using contraceptive methods were correctly classified. About $79.1 \%$ correct predictions of overall married women in reproductive age group is modeled by using binary logistic regression model.

Table 3.4. Hosmer-Lemeshow Test.

\begin{tabular}{lll}
\hline Chi-square value & DF & Significance level \\
\hline 10.188 & 8 & 0.252 \\
\hline
\end{tabular}

Validation of Predicted Probability of Binary Logistic Regression Model
Table 3.5. Classification table.

\begin{tabular}{|c|c|c|c|c|}
\hline \multirow[t]{2}{*}{ Observed } & & \multicolumn{2}{|c|}{ Predicted } & \multirow{2}{*}{$\begin{array}{l}\text { Percentage } \\
\text { Correct }\end{array}$} \\
\hline & & Not use & use & \\
\hline Modern & Not use & 6826 & 421 & 94.2 \\
\hline contraceptive & Use & 1551 & 640 & 29.3 \\
\hline \multicolumn{2}{|c|}{ Overall percentage } & & & 79.1 \\
\hline
\end{tabular}

\subsection{Model Diagnostics: Outliers and Influential Observations}

The adequacy of the fitted model was checked for possible presence and treatment of outliers and influential values.

\section{Discussion}

The results from binary logistic regression analysis revealed that the factors age of women, region, place of residence, religion, wealth index, women's educational level, number of living children, desire for more children, women's work status, decision maker for modern contraception use and exposure to mass media have significant effects on married women's modern contraceptive use at 5\% significance level. However, the impact of husband's education level was found to be insignificant.

The result of the study showed that using modern contraceptive is significantly associated with age of women. Married women aged15-19,20-24, 25-29, 30-35 and $40-44$ were more likely to use modern contraception (8.123, $6.952,5.363,5.017,4.901$, and 2.773 times respectively) than those aged $45-49$ years which is the reference category. This indicates that odds of using modern contraception decrease as age of married women increase. This result maintains what is stated with studies done in Bangladesh as in (Khan, 1997).

Modern contraceptive use of married women has significant association with geographical regions. The odds of using modern contraceptive of married women in Amhara are 2.227 times (OR: $2.227, \mathrm{CI}$ : $(1.674,2.964))$ higher than that the odds using modern contraceptive of married women in Addis Ababa. It is also observed that married woman in Somalia were $79 \%$ less likely to use modern contraception than married women in Addis Ababa while the odds of married women living in Tigray, Afar and Harari were not significant, indicating that modern contraceptive use in these region is similar to Addis Ababa.

The number of living children was another factor that was significantly associated with current use of modern contraceptives in the study. Married women with no living children were $64 \%$ less likely to use modern contraception (OR: $0.360, \mathrm{CI}:(0.286,0.454))$ than married women with 2 and more living children. The odds of married women with one child were $16.2 \%$ less likely to practice modern contraception than those with two or more children. This finding suggests the importance of motivation for limiting family size. Women will practice contraception when they meet their desired family size. This finding is similar to a study in Uganda. It shows that contraceptive use increased 
with parity (Gupta, et al., 2003). Therefore, the odd of using modern contraception was high among married women who had living children from 1 child and above.

In addition, the desired for more children had a statistically significant effect on modern contraceptive use. Married women who wanted no more children were $36 \%$ less likely to use modern contraception than those women who desired to have another child.

This finding is similar to a study in India, where it was found that women would not practice any method if they still desired additional children (Roy et al, 2003).

Women's education had also a significant effect on modern contraceptive use among married women. The odds of using modern contraception for married women who have no primary education were 23.4 percent less likely to use modern contraception than those women who have secondary education and higher. Generally, use of modern contraceptive is likely to increase when married woman's educational level increases. This is because they understand the benefits and the side effects of contraceptives better when they are more educated. That means women with more formal education were more likely to practice family planning than those with less education. Women's education was very important because they can read (newspaper, magazine, health information etc), they will have knowledge especially the ones relating to family planning and realize the benefits of using contraception. Furthermore, women with more education probably appreciate better health and economic status advantages of small family sizes and they are more likely to protect themselves from unwanted pregnancy.

Married women's wealth status shows statistically significant effect on the utilization of modern contraception, the higher the level of women's wealth status, the more they used modern contraception. Married women who were in the poor and middle wealth status were less likely to use modern contraception ( $61 \%$ and $38 \%$ respectively) than those in the rich wealth status which is the reference group. This finding is similar to that of a study in Kinshasa, Zaire, which shows that the use of contraception rises steadily as economic status increases (Shapiro, 1994). In addition, women's working status plays an important role in determining whether or not they use modern contraception. Women engaged in work were more likely to practice modern contraception than those who were not working.

The likelihood of using modern contraception is significantly associated with respondents religious affiliations $(\mathrm{p}<0.001)$. Orthodox believers were 2.274 times (OR: 2.274, CI: $(1.469,3.522))$ more likely to use modern contraceptives than those who had other religion. Protestant believers were 68 percent times more to use modern contraception than those in other religion. The likelihood of using contraceptive methods among married women who were followers of Muslim was not significantly different from those who were followers of religions other than Orthodox, protestant and Muslim.

In addition, the effect of place of residence was found to be significant. The odds of married women who desired in the rural areas are $94.4 \%$ more likely to use modern contraceptive compared to those married women living in urban areas. In the real situation in Ethiopia, it is easier for married women in urban area to get access to family planning information and services than those resided in rural areas. Thus, they would be expected to more use modern contraceptive than those living in rural areas.

It is surprising to find that husband's educational level had no significant effect on modern contraception. However, the odds ratio is positive. Formal education of the husband is also viewed as fundamental to individual understanding and to adopt method of contraceptive use. The finding suggests that contraceptive use among married women in Ethiopia depends on women's demographic and socioeconomic characteristics including number of living children, desire for more children, education, occupation, and wealth status. It is no matter what the husband's education level is.

Married women reported decision to be done by husband alone on issue related to family planning were $30.9 \%$ less likely to be current user of modern contraceptives compared to those reported joint decisions with their husbands. This result is consistent with the previous studies done in different parts of Ethiopia showed significant association of men's involvement with family planning methods use (Terefe A. and Larson C. P., 1993)

Regarding mass media exposure, it was found that married women who received information from any mass media were significantly more likely to use modern contraception. This is similar to previous studies showing that exposure to mass media can be an important means to improve knowledge and initiate women to practice any form of modern contraception (Gupta et al., 2003).

\section{Conclusion}

Although knowledge on modern contraceptive is significantly high with around 94 percent amongmarried women of reproductive age but utilization rate is very low with $23 \%$ of married women of reproductive age. The likelihood of being current user of modern contraceptives by a woman increased with increase in education level, having large number of living children, and woman participation in decision- making regarding using modern contraception. The main conclusion that was derived from the results of this study, was that, married women's were making rational choices in terms of their modern contraceptive use. This was demonstrated by the fact that there was at least one variable in every category of these factors that was found to have a statistically significant effect on the current useof modern contraception among the currently married women of reproductive ages considered in this study.

\section{Recommendations}

Based on findings of this study, to enhance modern contraceptive use by married women of reproductive age in a study population it is recommended that education about the 
importance of having smaller families should be intensified in communities. Furthermore, campaigns to empower women such as emphasis on their education, encouraging gender balance by changing community attitude towards position/status of women in a household and in a society as a whole should be strengthened. This would improve their participation in household decisions including those related to fertility and contraceptive use. Since a woman's perception of her husband's opinion about contraceptive use had a significant influence on her contraception practice, it seems that a husband's attitudes act as a serious obstacle to a woman's contraceptive use (Rahayu et al, 2009). Therefore, policy makers responsible for national family planning programs need to target husbands by constructing a message that encourages male participation in family planning. This could be through involvement of males in family planning programs.

\section{Acknowledgement}

My special gratitude goes to my advisor, Prof. M.K. Sharma of Addis Ababa University for his encouragement, suggestions and constructive comments that develop my research abilities while conducting my Master's Thesis. Secondly, I offer my regards and blessings to Berhanu Teshome of Mekelle University, Berhanu Worku of Dilla University, Gutu Adugna and Kabatamu Tolosie of Arba Minch University, Negara Wakgari of Dire Dawa University and Henok Wako of Arba Minch University for their contributions in any respect for the completion of the Thesis.

Lastly, I would like to extend my gratitude to the Arba Minch University for offering me opportunity and financial support throughout the whole academic years.

Above all else, to God be the Glory!

\section{References}

[1] Amaha Haile, Fikre Enqueselassie, 2006. Influence of women's autonomy on couple's contraception usein Jimma town, Ethiopia. Ethiopian Journal of Health Development, 20(3), $1-7$

[2] Jane T. Bertrand (2003). Population reports. The INFO Project, Center for Communication Programs, the Johns Hopkins Bloomberg School of Public Health, Baltimore. Spring; 31(2):1-21.

[3] Central Statistical Authority (CSA), (2007) Summary and Statistical Report of the Population and Housing Census, Population Census Commission. Addis Ababa, Ethiopia.

[4] Cohen Barney (1998). The emerging fertility transition in sub-Saharan Africa, World Development 26(8):1431-1461.
[5] Ethiopian Demographic and Health Survey (2011). Central Statistics Agency, Addis Ababa, Ethiopia.

[6] Halvor Gille (1985). The World Fertility Survey: Policy Implications for Developing Countries. International Family Planning Perspective. Vol., 11, No. 1, 9-17

[7] Neeru Gupta, Charles Katende, and Ruth Bessinger(2003). Associations of Mass Media Exposure with Family Planning Attitudes and Practices in Uganda. Studies inFamily Planning, 34(1):19-31.

[8] Johnson-Hanks J.(2003). Education, ethnicity, and reproductive practice in Cameroon. Population 58(2), 153-179.

[9] David W. Hosmer and Stanley Lemeshow (1989). Applied Logistic Regression. John and Sons, Inc., W. H. (1993): Econometric Analysis. $2^{\text {nd }}$ Edition. New York, Macmillan.

[10] H.T. Abdullah Khan(1997). A hierarchical model of contraceptive use in urban and rural Bangladesh: Contraception, $55,91-96$

[11] Ria Rahayu, Iwu Utomo, and Peter McDonald (2009). Contraceptive use pattern among women in Indonesia, http:// www.fpconference2009.org.

[12] Roy, T. K., Ram, F., Parveen Nangia, Uma Saha and Nizamuddin Khan(2003). Can Women's Childbearing and Contraceptive Intensions Predict Contraceptive Demand? Finding from A Longitudinal Study in Central India. International family planning perspectives, 299(1):25-31.

[13] Shapiro David and B. Oleko Tambashe. (1994). The impact of women's Employment and Education on Contraceptive use and Abortion in Kinshasa, Zaire. Studies in Families Planning, 25 (2): $96-110$

[14] Shryock, H.S, and Siegel, J.S., 1976. The Methods and Materials of Demography. Studies in Population, Academic Press, California, USA.

[15] Speth, J.G. 1994. Towards a new global strategy viewpoint. People and Planet 3:34-36.

[16] Terefe A. and Charles P Larson, 1993. Modern contraception use in Ethiopia: Does involving husbands make a difference? American Journal of Public Health. 83(11):1567-71.

[17] James Trussell, and Kost, R.I. (1989) Age at marriage and age at first birth. Population Bulletin of the United Nations. New York, NY: United Nations.

[18] United Nation Development Program. Human Development Report, 1992. New York, NY: Oxford University Press; 1992.

[19] The United States Agency for International Development(2009). Achieving the Millennium Development Goals: The contribution of family planning in Cameroon. Health Policy Initiative. 